\title{
QUALIDADE DA APLICAÇÃO AÉREA LÍQUIDA COM UMA AERONAVE AGRÍCOLA EXPERIMENTAL NA CULTURA DA SOJA (Glycine Max L.)
}

\author{
ELTON F. DOS REIS ${ }^{1}$, DANIEL M. DE QUEIROZ ${ }^{2}$, JOÃO P. A. R. DA CUNHA ${ }^{3}$, \\ SUELI M. F. ALVES ${ }^{4}$
}

\begin{abstract}
RESUMO: Os avanços da tecnologia de aplicação aérea de agroquímicos têm-se dado na direção de redução do volume de calda, o que pode ocasionar má distribuição e consequente deposição irregular. O presente trabalho teve como objetivo avaliar a qualidade da aplicação de calda de pulverização em aplicação aérea, na cultura da soja (Glycine Max L.). Para a aplicação, foi utilizada uma aeronave agrícola experimental, aplicando um volume de calda de $20 \mathrm{Lha}^{-1}$. Para a determinação dos volumes depositados nas folhas do terço superior, médio e inferior das plantas de soja, foi utilizado corante alimentício azul brilhante adicionado à calda de pulverização. Estas folhas foram lavadas, e o volume determinado por espectrofotometria. Para a obtenção do espectro de gotas, foram utilizados alvos artificiais constituídos por papel hidrossensível, distribuídos no terço superior e médio das plantas. Os dados foram submetidos à análise de variância de fator único, considerando as diferentes posições na planta, e cartas de controle foram feitas a partir dos limites inferior e superior de controle. A aplicação aérea de calda de pulverização na cultura da soja apresentou menores valores de diâmetro da mediana volumétrica, amplitude relativa e cobertura no terço médio em relação ao terço superior da cultura da soja. Houve menor deposição da calda de pulverização no terço inferior. Os indicadores de cobertura da calda de pulverização demonstraram que a aplicação aérea com a aeronave agrícola experimental avaliada não se encontra sob controle estatístico de processo, ou seja, fora do padrão de qualidade.
\end{abstract}

PALAVRAS-CHAVE: tecnologia de aplicação, aviação agrícola, controle estatístico.

\section{LIQUID AERIAL PESTICIDE APPLICATION QUALITY WITH AN EXPERIMENTAL AGRICULTURAL AIRCRAFT IN SOYBEAN CROP (Glycine Max L.)}

\begin{abstract}
Advances in aerial pesticide application technology of chemicals have been given in the direction of reducing the syrup volume, which can cause poor distribution and consequent irregular deposition. This study aimed to evaluate the quality of the syrup spray on aerial application in soybean crop (Glycine Max L.). For the application, an experimental agricultural aircraft was used, applying a spray volume of $20 \mathrm{~L} \mathrm{ha}^{-1}$. A bright blue food coloring added to the syrup spray was used for the determination of the volumes stored in the leaves of the upper third, middle and bottom of the soybean plants. These leaves were washed, and the volume determined by spectrophotometry. To obtain the drops spectrum were used artificial targets set by water sensitive paper, distributed in the middle and upper third of the plants. Data were submitted to analysis of variance with a single factor, considering the different positions in the plant, and control cards were made from the lower and upper control limits. The aerial application of syrup spray in the soybean crop had lower values of the volumetric median diameter, relative amplitude and coverage on the middle third in relation of the upper third of the soybean crop. There was less of the syrup spray deposition in the lower third. The coverage indicators of the syrup spray showed that aerial application with the evaluated agricultural experimental aircraft is not under statistical process control, in other words, outside of the quality standard.
\end{abstract}

KEYWORDS: application technology, agricultural aviation, statistical control.

\footnotetext{
${ }^{1}$ Eng ${ }^{o}$ Agrícola, Prof. Doutor, Depto. de Engenharia Agrícola, Universidade Estadual de Goiás, Anápolis - GO, fialhoreis@ ueg.br.

${ }^{2}$ Eng $^{\mathrm{O}}$ Agrícola, Prof. Doutor, Depto. de Engenharia Agrícola, Universidade Federal de Viçosa - MG, dmqueiroz@gmail.com.

${ }^{3}$ Eng ${ }^{\circ}$ Agrícola, Prof. Doutor, Instituto de Ciências Agrárias, Universidade Federal de Uberlândia - MG, jpcunha@iciag.ufu.br.

${ }^{4}$ Eng $^{\underline{a}}$ Agrônoma, Profa. Doutora, Depto. de Engenharia Agrícola, Universidade Estadual de Goiás, Anápolis - GO, suelifreitas@ueg.br.

Recebido pelo Conselho Editorial em: 14-8-2009
}

Aprovado pelo Conselho Editorial em: 8-9-2010 


\section{INTRODUÇÃO}

Dentre as várias etapas que constituem o processo de produção agrícola, a aplicação de defensivos é uma das mais exigentes, pois deve atender não somente ao tratamento da área cultivada, mas também a cuidados com a preservação do ambiente (CHRISTOFOLETTI, 1999).

Na maioria das vezes, durante o controle químico de pragas, doenças e plantas daninhas, dá-se muita importância ao produto fitossanitário e pouca atenção à técnica de aplicação. A consequência é a perda de eficácia, quando não o fracasso total do tratamento, com superdosagens ou subdosagens, que levam à perda de produção e a danos ao ambiente e à própria saúde humana (CUNHA \& RUAS, 2006). Com isso, além de conhecer o produto a ser aplicado, também é necessário dominar a forma adequada de aplicação, de modo a garantir que o produto alcance o alvo de forma eficiente, minimizando-se as perdas e não provocando alteração ao meio ambiente (CUNHA et al., 2005).

A cobertura e a deposição do ingrediente ativo sobre o alvo são importantes, e quando se trata de doenças causadas por fungos, que começam suas infestações pelas partes mais próximas do solo, torna-se alvo de estudos mais avançados (CHAIM et al., 1999). A qualidade da cobertura do alvo está condicionada ao diâmetro de gotas. As de menor diâmetro proporcionam maior penetração entre as folhas das culturas (CUNHA et al., 2006); entretanto, ao se reduzir o diâmetro das gotas para aumentar a cobertura do alvo, com o mesmo volume de aplicação, maior é a interferência do vento, causando deriva, e da temperatura e umidade do ar, causando perdas por evaporação (CHRISTOFOLETTI, 1999). Estima-se que grande parte dos produtos pulverizados sobre as lavouras são perdidos no momento da aplicação.

Em geral, recomenda-se que aplicações com volumes muito baixos sejam realizadas com metodologias de controle da evaporação da água ou mesmo a substituição da água por outro meio. Um exemplo dessa técnica é o emprego de óleo como aditivo nas aplicações em baixo volume, o que acorre em aplicação aérea. ANTUNIASSI \& BAIO (2004) citam que, na aplicação aérea de fungicidas para controle de ferrugem e doenças de final de ciclo na cultura da soja, os volumes podem variar de 5 a $30 \mathrm{~L} \mathrm{ha}^{-1}$. CUNHA \& CARVALHO (2005), avaliando o efeito da adição de adjuvantes na calda de pulverização, mostraram que a adição de adjuvantes alterou $o$ comportamento da distribuição e aumentou a deposição da calda no alvo.

Estudos sobre padrões de deposição de pulverizações indicam grande variabilidade de deposição dos agrotóxicos ao longo das faixas de aplicação, o que diminui a eficácia dos tratamentos (GUPTA \& DUC, 1996; PERGHER et al., 1997). De maneira geral, a deposição é menor nas partes mais baixas e internas do dossel das culturas. No caso de fungicidas, esta desuniformidade proporciona baixa eficácia no controle das doenças, principalmente no caso de fungicidas de contato, que requerem cobertura uniforme de toda a planta.

Aliado ao aumento da demanda de alimentos, cresceu o grau de exigência dos consumidores, o que tornou necessária uma nova postura do produtor para satisfazer os mercados. O consumidor tem-se tornado cada vez mais exigente quanto à qualidade do produto final. Segundo BONILLA (1994), o controle de qualidade é perfeitamente adaptável ao sistema de produção agrícola, o qual, com a correção e a eliminação de desperdícios e falhas, redução de custos e aumento da produtividade, trará vantagens numerosas na competitividade do campo num futuro próximo.

O controle estatístico do processo (CEP) é um conjunto de técnicas úteis para resolução de problemas, alcance da estabilidade do processo e aumento da capacidade por meio da redução da variabilidade (MONTGOMERY, 1991). O CEP tem como objetivo detectar rapidamente alterações dos parâmetros de determinados processos para que os problemas possam ser corrigidos antes que muitos itens não conformes sejam produzidos (MINGOTI \& FIDELIS, 2001).

De acordo com FERNANDES et al. (2000), sob o ponto de vista econômico, qualidade é a produção de serviços e de produtos a custos compatíveis com a atividade, com a obtenção de lucros para o produtor e que satisfaçam às necessidades dos consumidores. Sob o ponto de vista 
agronômico, qualidade é a realização das operações agrícolas ou a obtenção de produtos que estejam adequados às especificações ou a padrões agronômicos recomendados. SUGUISAWA et al. (2007), trabalhando com qualidade de aplicação de herbicida em lavoura de trigo, mostraram que o processo apresentava irregularidade e grande variabilidade, necessitando de melhorias, mas como os produtos utilizados eram sistêmicos, considerou como razoável a qualidade da operação.

A aplicação aérea de defensivos é uma ferramenta valiosa na agricultura, quando realizada dentro de critérios técnicos bem definidos. Nesse contexto, o objetivo desta pesquisa foi avaliar a qualidade da aplicação de calda de pulverização em aplicação aérea na cultura da soja (Glycine Max L.).

\section{MATERIAL E MÉTODOS}

A área em estudo situa-se na fazenda Capão do Cariru, município de Abadiânia - GO, em uma área de 15 hectares cultivada com soja (Glycine max L. Merril) da cultivar valiosa, durante oito safras consecutivas. O solo no local é classificado como Latossolo Vermelho-Amarelo, textura média, apresentando relevo suave.

A aplicação foi realizada com uma aeronave agrícola experimental, modelo acrobata da empresa Inglaer, monoplano de asa baixa afilada, motor de $194 \mathrm{~kW}$ (260 hp), velocidade de $160,9 \mathrm{~km} \mathrm{~h}^{-1}$ (100 milhas $\left.\mathrm{h}^{-1}\right)$, com evolução do voo em carrossel e altura de voo em relação à cultura de $3 \mathrm{~m}$. A barra de pulverização da aeronave estava composta por oito atomizadores de tela rotativa Micronair, modelo AU 5000, com ângulo das hélices de $35^{\circ}$. A aplicação foi realizada com volume de calda de $20 \mathrm{~L} \mathrm{ha}^{-1}$, pressão de trabalho de $206 \mathrm{kPa}$ (30 PSI) e largura de faixa de $16 \mathrm{~m}$, auxiliada com uso de DGPS. Foi adicionado à calda de pulverização 2,5\% v/v do adjuvante éster metílico de óleo de soja, para simular condições reais de uma aplicação aérea na região e a visando uma produção de gotas de tamanho mais uniforme. A soja encontrava-se com altura média de 0,80 m e no estádio fenológico R3.

As amostras de deposição de calda para estudo da qualidade da aplicação foram coletadas em um talhão manejado sob plantio direto, em uma malha regular de amostragem de $46 \mathrm{~m} \mathrm{x} 46 \mathrm{~m}$, totalizando 79 pontos amostrais (repetições), sendo que cada ponto foi georreferenciado para, em seguida, fazer as coletas de amostras na altura do terço superior, médio e inferior das plantas. Após a coleta, as amostras foram armazenadas, vedadas e transportadas para o laboratório, onde foi quantificada a deposição. REICHARD et al. (1992) argumentam sobre a dificuldade de obter, em experimentos com pulverização em campo, dados com um grau de confiança aceitável; logo, sugerem um aumento do número de amostras, razão pela qual, neste experimento, utilizou-se um grande número de pontos amostrais.

A navegação em campo foi feita com a utilização de um sistema de direcionamento por DGPS, "Omnistar SST", com o sistema de correção diferencial em tempo real via satélite, e um computador portátil, Pocket PC Ipaq 3850, munido de um programa de navegação "Field Rover II", que realizou a gravação das passadas.

Durante a aplicação, a temperatura ambiente era de $28{ }^{\circ} \mathrm{C}$, a umidade relativa do ar, $56 \%$, e a velocidade do vento, entre 5,4 e $6,0 \mathrm{~km} \mathrm{~h}^{-1}$. Todos os parâmetros foram monitorados com um termo-higro-anemômetro da marca LUTRON, modelo LM-8000, com coletas em intervalos de tempo tomados aleatoriamente durante a aplicação.

Para análise do espectro de gotas, foram utilizadas etiquetas hidrossensíveis. Os alvos foram distribuídos nos terços superior e médio da planta, com uma etiqueta por ponto, sendo avaliado o diâmetro da mediana volumétrica (DMV), amplitude relativa (AR) e percentagem de cobertura (\%C). A análise foi feita utilizando o programa computacional "CIR" (Conteo y tipification de impactos de pulverización) versão 1.5 2002, após a digitalização das imagens das etiquetas.

Para a avaliação da deposição, foi analisada a distribuição da calda de pulverização por meio da quantificação de um traçador, adicionado à mesma. Em cada planta de soja, no estádio R3, foram 
coletados dois folíolos na parte central, ao acaso, em três posições da planta (terços inferior, médio e superior), em cinco plantas, em um raio de $1 \mathrm{~m}$ próximo ao ponto georreferenciado. As folhas foram coletadas e armazenadas de acordo com a altura correspondente de cada parcela, em sacos plásticos. Em seguida, as amostras foram transportadas para o laboratório, para a remoção do depósito, utilizando $10 \mathrm{~mL}$ de água deionizada por folha. A solução da lavagem foi armazenada em recipientes de vidro, para posterior determinação quantitativa do depósito do traçante. Os folíolos tiveram sua área medida por meio de digitalização e análise no programa computacional "Image Tool" versão 3.0.

Para análise de deposição, foi utilizada uma solução traçadora adicionada à calda, constituída do corante Azul Brilhante (FD\&C Blue n.1), catalogado internacionalmente pela Food, Drug \& Cosmetic, na proporção de $1.790 \mathrm{mg} \mathrm{L}^{-1}$, conforme metodologia proposta por PALLADINI et al. (2005). A determinação da quantidade do traçador depositada, em cada amostra, foi realizada com espectrofotômetro no comprimento de onda de $630 \mathrm{~nm}$ para o azul brilhante. Com o uso da curva de calibração, obtida por meio de soluções-padrão, os dados de absorbância foram transformados em concentração $\left(\mathrm{mg} \mathrm{L}^{-1}\right) \mathrm{e}$, de posse da concentração inicial da calda e do volume de diluição das amostras, determinou-se o volume retido no alvo. Logo após, foi feita, então, a divisão do depósito total pela área foliar de remoção, obtendo-se, assim, a quantidade em $\mu \mathrm{L} \mathrm{cm}^{-2}$ de folha.

Os dados foram submetidos à análise de variância de fator único, considerando as diferentes posições da planta, e comparados pelo teste de Tukey, a 5\% de probabilidade, quando significativo pelo teste $\mathrm{f}$. As cartas de controle foram feitas a partir da média (mean) do limite de controle inferior (LCL) e do limite de controle superior (UCL), elaboradas no programa Minitab®. Para estimar as linhas médias e os limites dos gráficos de controle, foram usadas as equações propostas por TRINDADE et al. (2000).

\section{RESULTADOS E DISCUSSÃO}

O diâmetro da mediana volumétrica (DMV) apresentou maiores valores para o terço superior da cultura da soja, sendo significativo a $1 \%$ de probabilidade, pelo teste $\mathrm{f}$. No terço superior, o DMV foi de $144,5 \mu \mathrm{m}$ e, no terço médio, foi de $125,4 \mu \mathrm{m}$. Possivelmente, isso ocorreu devido à maior capacidade de penetração no dossel das gotas menores, que provavelmente foram produzidas pelo deslocamento da corrente de ar após a passagem da aeronave, depois que a gota saiu do micronair. Diferentemente de qualquer equipamento de aplicação terrestre, um avião agrícola possui características próprias e específicas, principalmente turbulência e aerodinâmicas, produzidas por toda a estrutura e componentes de um avião (asas, fuselagem, hélice e equipamento de aplicação) que têm importância na geração, dispersão e deposição das gotas sobre o alvo (OZEKI, 2006). Estas características e a sensibilidade do papel possivelmente afetaram a variabilidade dos dados de DMV, que apresentou um coeficiente de variação de 19,9\%. Esse espectro de gotas está dentro dos padrões apresentados em aplicação aérea.

A amplitude relativa apresentou menor valor para o terço superior da cultura da soja, sendo significativo a $1 \%$ de probabilidade, pelo teste f. Para aumentar a qualidade da pulverização, deve-se melhorar os padrões de gotas aplicadas, especialmente no que diz respeito à homogeneidade do espectro de gotas. Quanto maior o valor da amplitude relativa, maior será a faixa de tamanho de gotas. O terço superior apresentou valor médio de amplitude relativa de 0,869 e, no terço médio, o valor foi de 0,997 , com um coeficiente de variação de 30,8\%. Espectro de gotas homogêneo tem valor de amplitude relativa tendendo a zero. Os valores de amplitude relativa e DMV devem ser analisados conjuntamente para a caracterização da pulverização. Isoladamente, o DMV fornece um valor de referência, sem indicar a dispersão dos dados em torno da média. A amplitude relativa indica a homogeneidade do tamanho das gotas. Logo, para a aplicação no terço médio, houve uma redução do DMV e da homogeneidade das gotas aplicadas, apresentando maior média de amplitude relativa. 
Os valores de amplitude relativa reduzidos mostram que os atomizadores rotativos produziram gotas com menor coeficiente de variação, ou seja, gotas com maior uniformidade de tamanho. $\mathrm{O}$ vento, durante a aplicação, estava no sentido perpendicular (vento de través) à direção do voo, conforme OZEKI (2006), fazendo com que as faixas se sobreponham, minimizando o efeito negativo da turbulência provocada pela aerodinâmica da aeronave.

O percentual de cobertura apresentou maior valor para o terço superior da cultura da soja, sendo significativo a $1 \%$ de probabilidade, pelo teste $\mathrm{f}$. Para que o defensivo agrícola alcance boa eficiência na aplicação e atinja o resultado esperado, é necessário que haja cobertura eficiente em todas as partes da planta. Geralmente, a cobertura na parte inferior das plantas é prejudicada, devido ao grande obstáculo que é a parede formada pela massa foliar, ocasionando grandes perdas nas lavouras pela dificuldade de controle de doenças e pragas, favorecendo sua disseminação para outras áreas. A cobertura apresentou valores de 3,47\% da área no terço superior e 2,09\% no terço médio da cultura, valores que apresentaram grande variabilidade, com coeficiente de variação de $53,8 \%$. Estudos sobre padrões de deposição de pulverizações indicam grande variabilidade de deposição dos agrotóxicos ao longo das faixas de aplicação, o que diminui a eficácia dos tratamentos (GUPTA \& DUC, 1996; PERGHER et al., 1997). Dessa forma, se as aplicações são realizadas de maneira ineficiente, provavelmente serão necessárias aplicações complementares para que o controle de pragas e doenças seja efetivo.

A análise de variância mostrou que houve efeito significativo na deposição ao longo do dossel da cultura da soja, sendo significativo a $5 \%$ de probabilidade, pelo teste f. Na Tabela 1, é mostrado que a aplicação aérea proporcionou diferença na quantidade de calda retida entre as posições do dossel das plantas de soja. Os terços superior e médio apresentaram a mesma quantidade de calda retida, indicando boa deposição, mas no terço inferior o valor de deposição foi menor. Esse resultado proporcionou menor distribuição de calda no inferior do dossel da cultura, condição indesejada principalmente quando o agrotóxico é usado para controle de doenças causadas nas partes mais baixas das plantas. Este menor valor pode causar redução no controle de doenças causadas por fungos, pois a cobertura e a deposição do ingrediente ativo sobre o alvo são importantes, principalmente, quando se trata de doenças causadas por fungos, que começam suas infestações pelas folhas mais baixas da planta até atingir a planta inteira (CHAIM et al., 1999; GODOY, 2004)

Quando comparada a deposição da calda de pulverização com a cobertura, mostra-se que houve menor cobertura no terço médio, mas para a deposição não foram verificadas diferenças significativas entre o terço superior e o médio, como mostrado na Tabela 1, o que possivelmente ocorreu devido à falta de precisão na metodologia do papel sensível, pois ele foi colocado próximo à folha com um número suficiente de pontos amostrais. Estes valores de deposição são de grande interesse, pois mostram a quantidade de produto que efetivamente atingiu o alvo da aplicação. Observou-se ainda que os valores do coeficiente de variação para os terços superior e médio foram, respectivamente, de $43,7 \%$, e o terço inferior apresentou um coeficiente de variação de $66,5 \%$. A parede formada pela massa foliar foi a causadora dessa variação, pois em vários pontos não houve deposição de calda no terço inferior.

TABELA 1. Efeito da pulverização aérea na deposição de calda $\left(\mu \mathrm{L} \mathrm{cm}^{-2}\right)$, nas diferentes alturas da cultura da soja. Effect of aerial spraying in the deposition of water $\left(\mu \mathrm{L} \mathrm{cm} \mathbf{c m}^{-2}\right)$ at different times in soybean crop.

\begin{tabular}{cccc}
\hline Aplicação aérea & Terço superior & Terço médio & Terço inferior \\
\hline Calda com adjuvante & $0,0505 \mathrm{a}$ & $0,0504 \mathrm{a}$ & $0,0335 \mathrm{~b}$ \\
\hline
\end{tabular}

Médias seguidas pela mesma letra não diferem entre si, a 5\% de probabilidade, pelo teste de Tukey.

Na Figura 1, são apresentadas as cartas de controle das médias para o diâmetro da mediana volumétrica. Observa-se que, em ambas as situações, o processo encontra-se fora de controle estatístico. Entre os processos de geração de gotas, destaca-se que os atomizadores rotativos, muito 
utilizados em aplicação aérea, são os que apresentam maior uniformidade das gotas. Contudo, provavelmente, em função da interação entre as gotas e o ar, principalmente devido à turbulência da aeronave, ocorreu grande variabilidade de tamanho de gotas na área. O diâmetro das gotas será sempre o que definirá ou determinará de que maneira, ou como, o alvo será atingido, favorecendo ou não a deposição em quantidade e qualidade suficientes para o sucesso da aplicação.
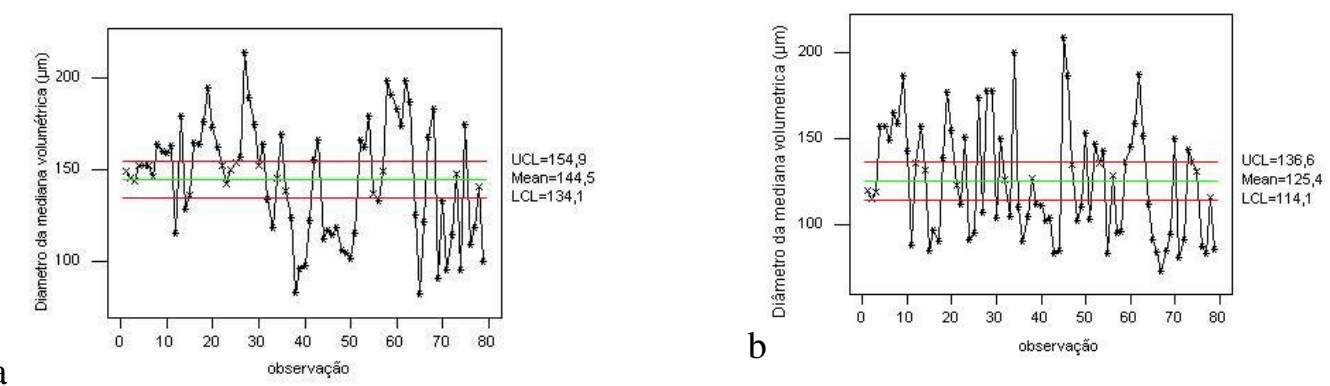

FIGURA 1. Carta de controle para o diâmetro da mediana volumétrica da calda de pulverização aérea: a) terço superior; b) terço médio da cultura da soja. Letter of control to the diameter of the median volume of aerial syrup spraying: a) upper third b) middle third of the soybean crop.

As cartas de controle para a variável amplitude relativa (Figura 2) indicam que o processo também se encontra fora de controle, visto que há pontos que saem dos limites nas cartas para os terços superior e médio da cultura da soja. Para aumentar a qualidade da pulverização, deve-se melhorar os padrões de gotas aplicadas, especialmente no que diz respeito à homogeneidade do espectro de gotas. Contudo, é fundamental também manter esse espectro ao longo da área aplicada. Espectro de gotas homogêneo tem valor de amplitude relativa tendendo a zero. Logo, o terço superior apresentou melhor espectro de gotas, mas com o processo fora de controle.

Considerando que em aplicação aérea utilizando os atomizadores rotativos e adjuvantes adicionados à calda, o espectro de gotas é mais homogêneo, mesmo assim o processo permaneceu fora de controle, com quase todos os pontos fora do limite de controle, o que possivelmente afetará a eficácia do tratamento. Destaca-se que, nesta avaliação das cartas de controle, não está sendo avaliada a amplitude relativa em si, mas sua variabilidade entre os pontos amostrais. Apesar de os valores médios de amplitude relativa não serem altos, o que se percebe é que ocorreu grande variação ao longo da área.

a

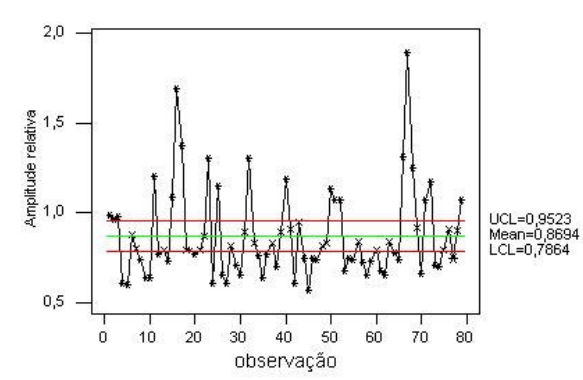

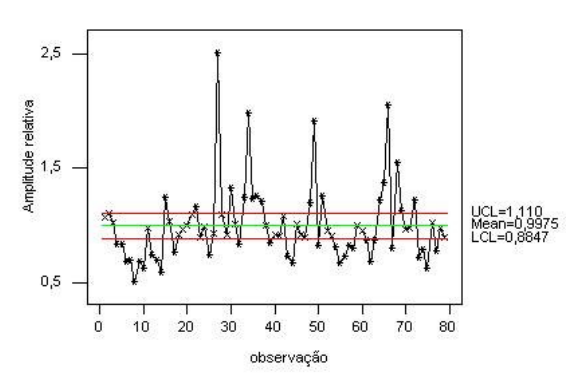

b

FIGURA 2. Carta de controle para a amplitude relativa da calda de pulverização aérea: a) terço superior; b) terço médio da cultura da soja. Letter of control to the relative amplitude of the aerial syrup spraying: a) upper third b) middle third of the soybean crop.

Na Figura 3, são apresentadas as cartas de controle da média para a cobertura dos terços superior e médio da cultura da soja. Ela também está fora de controle, pois a maioria dos pontos ultrapassa os limites inferior e superior de controle. Em geral, é comum que as partes inferiores apresentem menor cobertura, devido à dificuldade de penetração das gotas na massa foliar. 
Consequentemente, poderá haver menor controle de doenças, contudo quanto menor essa diferença entre as partes superior e inferior, melhor será o tratamento. Dessa forma, é preciso buscar alternativas que permitam incrementar a deposição no baixeiro. De forma geral, gotas pequenas são facilmente transportadas pelo vento, porém propiciam maior cobertura do alvo, condição desejada, sobretudo, quando da utilização de agrotóxicos de contato (CUNHA \& RUAS, 2006).
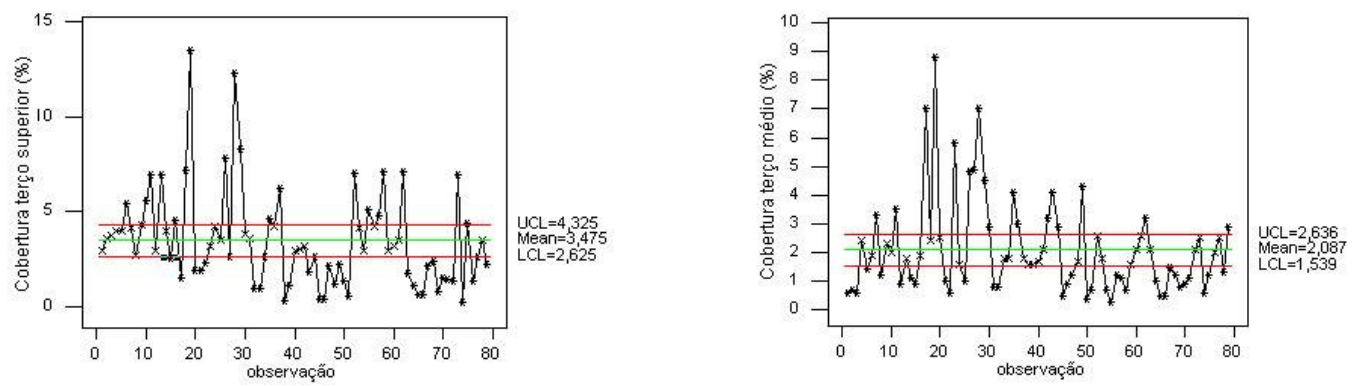

a

b

FIGURA 3. Carta de controle para cobertura da calda de pulverização aérea: a) terço superior; b) terço médio da cultura da soja. Letter of control to the covering of the aerial syrup spraying: a) upper third b) middle third of the soybean crop.

Na Figura 4, são apresentadas as cartas de controle das médias para a deposição da calda de pulverização nos terços superior e médio da cultura da soja. Observa-se que, em ambas as situações, o processo encontra-se fora de controle. Nesse sentido, é necessário melhorar a qualidade do processo, pois o objetivo da tecnologia de aplicação é colocar a quantidade certa de ingrediente ativo no alvo desejado, com máxima eficiência e da maneira mais econômica possível, sem afetar o meio ambiente. Resultados semelhantes foram encontrados por SUGUISAWA et al. (2007), trabalhando com qualidade de aplicação de herbicida em lavoura de trigo.
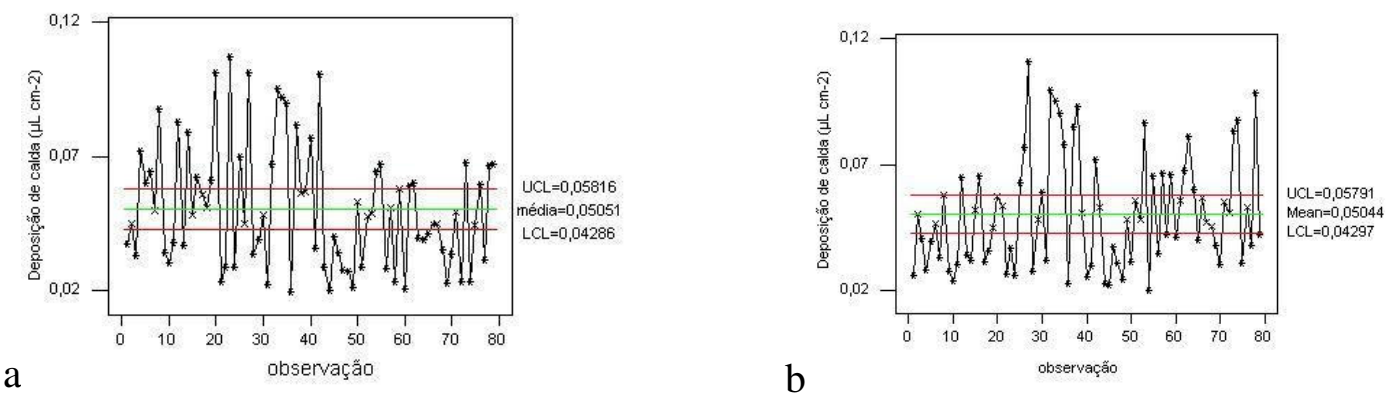

FIGURA 4. Carta de controle para deposição da calda de pulverização aérea: a) terço superior; b) terço médio da cultura da soja. Letter of control to the spray deposition of aerial syrup spraying: a) upper third b) middle third of the soybean crop.

Com relação à deposição de calda no terço inferior, a carta de controle mostra novamente que o sistema se encontra fora de controle (Figura 5). Ocorreu alta variabilidade na deposição no terço inferior, devido à parede formada pela massa foliar, pois em vários pontos não houve deposição de calda. Esta falta de controle do processo pode causar redução no controle de doenças, principalmente quando se trata de doenças causadas por fungos.

A análise das cartas de controle mostra que ocorreu grande variabilidade entre os 79 pontos amostrais. A aplicação de agroquímicos com volumes reduzidos implica a necessidade de maior cuidado com o processo de distribuição do líquido. Os atomizadores de tela rotativo são dispositivos de qualidade reconhecida na geração de gotas uniformes. Contudo, a disposição dos mesmos na barra da aeronave e a interação das gotas com o ar e com a cultura podem levar à 
desuniformidade de aplicação. Além disso, por se tratar de uma aeronave experimental, o efeito do processo de turbulência ainda é pouco conhecido, o que também pode ter colaborado com o resultado apresentado.

A distribuição das gotas será o que sempre definirá a deposição de calda no dossel da cultura. Nesse enfoque, ao observar as cartas de controle como método de avaliar a aplicação, entende-se que o controle de qualidade dessa operação precisa ser revisto, pois os valores encontram-se com alta variação. Há a necessidade de se aprofundar os estudos sobre o desempenho desta aeronave, com o objetivo de tornar a aplicação mais uniforme ao longo das áreas aplicadas. Destaca-se que esse resultado ocorreu para uma aeronave protótipo, construída com o propósito de servir de teste antes da fabricação em escala industrial, ou da comercialização.

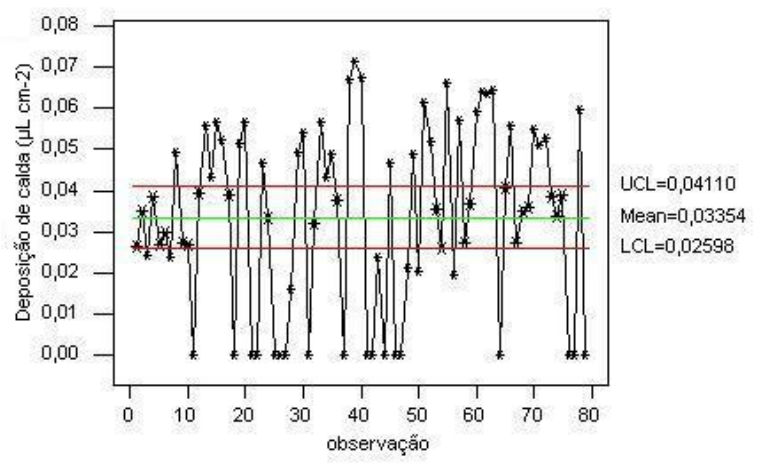

FIGURA 5. Carta de controle para deposição da calda de pulverização aérea no terço inferior da cultura da soja. Letter of control to the spray deposition of aerial syrup spraying in the lower third of the soybean crop.

\section{CONCLUSÕES}

A aplicação aérea de calda de pulverização na cultura da soja apresentou menores valores de diâmetro da mediana volumétrica, amplitude relativa e cobertura no terço médio em relação ao terço superior da cultura.

Houve menor deposição da calda de pulverização no terço inferior da cultura da soja.

Os indicadores de cobertura da calda de pulverização demonstraram que a aplicação aérea com a aeronave experimental avaliada não se encontra sob controle estatístico de processo, ou seja, fora do padrão de qualidade sob ponto de vista estatístico.

\section{AGRADECIMENTOS}

À Coordenação de Aperfeiçoamento de Pessoal de Nível Superior (CAPES), pela concessão de bolsa de estudo ao primeiro autor, por meio do Programa de cooperação acadêmica - Procad.

\section{REFÊRENCIAS}

ANTUNIASSI, U.R.; BAIO, F.H.R. Tecnologia de aplicação de defensivos. In: VARGAS, L.; ROMAN, E.S. Manual de manejo e controle de plantas daninhas. Bento Gonçalves: Embrapa Uva e Vinho, 2004. p.145-184.

BONILLA, J.A. Qualidade total na agricultura: fundamentos e aplicações. 2.ed. Belo Horizonte: Centro de Estudos de Qualidade Total na Agricultura, 1994. 344 p.

CHAIM, A.; CASTRO, V.L.S.S. de; CORRALES, F.M.; GALVÃO, CABRAL, J.A.H.; CABRAL, O.M.R.; NICOLELLA, G. Método para monitorar perdas na aplicação de agrotóxicos na cultura de tomate. Pesquisa Agropecuária Brasileira, Brasília, v.34, n.5, p.741-747, 1999. 
CHRISTOFOLETTI, J.C. Considerações sobre a deriva nas pulverizações agrícolas e seu controle. São Paulo: Teejet, 1999. 15p.

CUNHA, J.P.A.R.; REIS, E.F.; SANTOS, R.O. Controle químico da ferrugem asiática da soja em função de ponta de pulverização e de volume de calda. Ciência Rural, Santa Maria, v.36, n.5, p.1360-1366, 2006.

CUNHA, J.P.A.R.; RUAS, R.A.A. Uniformidade de distribuição volumétrica de pontas de pulverização de jato plano duplo com indução de ar. Pesquisa Agropecuária Tropical, Goiânia, v.36, n.1, p.61-66, 2006.

CUNHA, J.P.A.R.; CARVALHO, W.P.A. Distribuição volumétrica de aplicações aéreas de agrotóxicos utilizando adjuvantes. Engenharia na Agricultura, Viçosa - MG, v.13, n.2, p.130-135, 2005.

CUNHA, J.P.A.R.; TEIXEIRA, M.M.; VIEIRA, R.F.; FERNANDES, H.C. Deposição e deriva de calda fungicida aplicada em feijoeiro, em função de bico de pulverização e de volume de calda. Revista Brasileira de Engenharia Agrícola e Ambiental, Campina Grande, v.9, n.1, p.133-138, 2005.

FERNANDES, R.A.T.; MILAN, M.; PECHE FILHO, A. Gerenciamento da qualidade em operações mecanizadas de um sistema de produção de cana-de-açúcar. Engenharia Agrícola, Jaboticabal, v.20, n.3, p.215-220, 2000.

GODOY, C.V. Aspectos técnicos de controle da ferrugem da soja. Revista Plantio Direto, Passo Fundo, n.84, p.18-21, nov./dez. 2004

GUPTA, C.P.; DUC, T.X. Deposition studies of a hand-held air assisted electrostatic sprayer. Transactions of the ASAE, St. Joseph, v.39, n.5, p.1633-1639, 1996.

MIGNOTI, S.A.; FIDELIS, M.T. Aplicando a geoestatística no controle estatístico de processo. Revista Produto \& Produção, Porto Alegre, v.5, n.2, p.55-70, 2001.

MONTGOMERY, D.C. Introduction to statistical quality control. New York: John Wiley, 1991. $677 \mathrm{p}$.

OZEKI, Y. Manual de aplicação aérea. São Paulo: Ed. do Autor, 2006.

PALLADINI, L.A.; RAETANO, C.G.; VELINI, E.D. Choice of tracers for the evaluation of spray deposits. Scientia Agrícola, Piracicaba, v.62, n.5, p.440-445, 2005.

PERGHER, G.; GUBIANI, R.; TONETTO, G. Foliar deposition and pesticide losses from three airassisted sprayers in a hedgerow vineyard. Crop Protection, Guildford, v.16, n.1, p.25-33, 1997.

REICHARD, D.L.; ZHU, H.; FOX, R.D.; BRAZEE, R. D. Computer simulation of variables that influence spray drift. Transactions of ASAE, Saint Joseph, v.35, p.1401-1407, 1992.

SUGUISAWA, J.M.; FRANDO, F.N.; SILVA, S.S.; PECHE FILHO, A. Qualidade de aplicação de herbicida em lavoura de trigo. Engenharia Agrícola, Jaboticabal, v.27, n.esp., p.41- 47, jan. 2007.

TRINDADE, C.; REZENDE, J.L.P.; JACOVINE, L.A.G.; SARTORIO, M.L. Ferramentas da qualidade: aplicação na atividade florestal. Viçosa: Universidade Federal de Viçosa, 2000. 124 p. 